\title{
Relationship between region abscess maxillofacial and climate in South Sulawesi
}

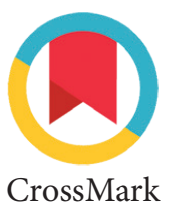

\author{
Andi Tajrin," Muhammad Ruslin, Abul Fauzi, Muhammad I. Rasul, Leen \\ DK. Seleng
}

\section{Abstract}

Objective: To determine the relationship between abscees development and climate in South Sulawesi Province.

Material and Methods: Medical records and x-ray of patient with mandibular abscees was collected from four hospital (Hasanudin University Hospital, Ibnu Sina Hospital, East of Indonesia University Hospital and Wahidin Sudirohusodo Hospital) and climate data of South Sulawesi Province. Patient data then investigate regarding to domicile and when it is reported.

Results: A total of 96 abscess cases was collected and investigated. Data analyzed showed $p>0.05$ for the incidences of abscess between dry and rainy season.

Conclusion: This study concluded there is no relationship between abscess development and seasons.
Department of Oral and Maxillofacial Surgery, Faculty of Dentistry, Hasanuddin University, Makassar, Indonesian
${ }^{*}$ Correspondence to: Andi Tajrin, Department of Oral and Maxillofacial Surgery, Faculty of Dentistry, Hasanuddin University, Makassar, Indonesian tajrinumi@gmail.com

Recieved: 10 February 2019 Revised: 12 April 2019 Accepted: 29 August 2019 Available Online 1 December 2019

Keywords: Region abscess maxillofacial, Relationship to abscess and climate, Abscess growth during the monsoon season.

Cite this Article: Tajrin A, Ruslin M, Fauzi A, Rasul MI, Seleng LDK. 2019. Relationship between region abscess maxillofacial and climate in South Sulawesi. Journal of Dentomaxillofacial Science 4(3): 137-141. D0I: 10.15562/jdmfs.v4i3.922

\section{Introduction}

Periapical abscess is a collection of pus which is confined to the aveloar bone at the apex of the tooth root and has spread to surrounding tissue after the tooth has pulpitis, by expanding the infection into the periradicular tissue through the apical foramen. The pus is formed from white blood cells that have died because of an attack on the infection. The ground can drain into the gum area, causing swelling of the gums around the root of the tooth. ${ }^{1-4}$

On the day when the barometer pressure or temperature is low, there is an increase in the frequency of tooth abscesses. In conclusion, bioclimatic or seasonal conditions affect health because of the low barometric pressure, which results in an increase in the number of patients with dental abscesses. The prevalence of life time abscesses in the oral cavity is reported to be between $5 \%$ and $43 \%$ depending on the basic status of the health care system. The majority of oral abscesses are caused by pathogenic bacteria from the oral cavity, such as species streptococcus, staphylococcus species prevotella, eikenella corrodens and others that migrate through damaged root canal teeth or periodontal pockets into the bone. ${ }^{2}$

\section{Material and Methods Types of Research and Design Research}

Type of research used in this study is descriptive observational. The research design used in this study was cross sectional study.

\section{Research Sites and Times}

Research sites at Wahidin Sudirohudoso Hospital, Unhas Teaching Hospital, Ibnu Sina Hospital, East of Indonesia University Hospital and rainfall data at BMKG South Sulawesi were conducted in September 2018 - Done.

\section{Tools and Materials}

Materials used are in the form of status cards or x-ray data from the radiology department at Wahidin Sudirohudoso Hospital, Unhas Teaching Hospital, Ibnu Sina Hospital, East of Indonesia University Hospital about patients with oral abscesses, while the instruments used are pens, book and calculator to record and calculate prevalence.

\section{Sampling Technique}

Research uses non-probability sampling technique that is purposive sampling. 


\section{Research Data}

Results of the primary data are processed manually, then the data is presented in the form of tables and

\section{Table 1 Data on patients with abscess regions maxillofacial the} Ibnu Sina Hospital

\begin{tabular}{|c|c|c|}
\hline Time & Total & Diagnosis \\
\hline February 2010 & 1 & abscess Mandible \\
\hline May 2010 & 1 & abscess buccal \\
\hline August 2010 & 1 & abscess lingual \\
\hline July 2011 & 1 & abscess buccal \\
\hline August 2011 & 1 & abscess Mandible \\
\hline April 2012 & 1 & abscess Labio \\
\hline May 2012 & 1 & abscess Mandible \\
\hline June 2012 & 1 & Abscess gingiva \\
\hline November 2012 & 1 & Mandibular Abscess \\
\hline December 2012 & 2 & Mandibular Abscess \\
\hline January 2013 & 1 & Mandibular Abscess \\
\hline February 2013 & 2 & Mandibular Abscess \\
\hline March 2013 & 2 & Mandibular Abscess \\
\hline April 2013 & 3 & Mandibular Abscess \\
\hline September 2013 & 2 & $\begin{array}{l}\text { Mandibular Abscess \& } \\
\text { Submandibular }\end{array}$ \\
\hline October 2013 & 1 & Mandibular Abscess \\
\hline December 2013 & 1 & Mandibular Abscess \\
\hline January 2013 & 1 & Abscess \\
\hline February 2014 & 1 & Mandibular Abscess \\
\hline March 2014 & 1 & Mandibular Abscess \\
\hline April 2014 & 1 & Parotid Abscess \\
\hline June 2014 & 4 & Mandibular \& Lingual Abscess \\
\hline August 2014 & 3 & Mandibular Abscess \\
\hline September 2014 & 1 & Mandibular Abscess \\
\hline October 2014 & 1 & Submandibular Abscess \\
\hline January 2015 & 1 & Mandibular Abscess \\
\hline April 2015 & 1 & Mandibular Abscess \\
\hline May 2015 & 1 & Abscess Mandibula \\
\hline July 2015 & 1 & Mandibular Abscess \\
\hline August 2015 & 3 & Mandibular Abscesses \& \\
\hline September 2015 & 1 & Mandibular Abscess \\
\hline October 2015 & 1 & Submandibular Abscess \\
\hline November 2015 & 1 & Mandibular Abscess \\
\hline February 2016 & 4 & $\begin{array}{l}\text { Mandibular Abscess, } \\
\text { Submandibula \& buccall }\end{array}$ \\
\hline March 2016 & 1 & Mandibular Abscess \\
\hline April 2016 & 1 & Mandibular Abscess \\
\hline May 2016 & 1 & Mandibular Abscess \\
\hline June 2016 & 4 & Mandibular Abscess \\
\hline August 2016 & 1 & Abscess \\
\hline
\end{tabular}

diagrams. Data analysis is done descriptively by making a systematic description of the conditions of the research results.

\section{Results}

This study was carried out by retrieving data from the East of Indonesia University Hospital, Ibn Sina Hospital, Unhas Teaching Hospital, and Wahidin Sudirohusodo Hospital in the month of November 2018. Data taken from the Hospital was in the form of medical records for patients abscess of the maxillofacial region from 2011 to 2018 . The process of retrieving the data is by recording important things such as the date of treatment, patient's name, patient's age, gender, and diagnosis. Based on the results of data collection there were a total of 92 cases of maxillofacial region abscess. Details of the number of maxillofacial region abscess cases can be seen in table 1 , table 2 , table 3 , and table 4 .

Other data was obtained from the Meteorology and Geophysics Agency (BMKG) in Makassar region IV. Data obtained in the form of rainfall data from 2011 to 2018. Detailed rainfall data in the city of Makassar from 2011 to 2018 can be seen in table 5 .

Total of 58 patients treated at Ibnu Sina Hospital with various diagnoses, such as mandibular abscesses, buccal abscesses, submandibular abscesses, labio abscesses, lingual abscesses, buccal abscesses, and gingival abscesses.

Total of 11 patients were admitted to the Hasanuddin University Teaching Hospital with various diagnoses, such as zygomaticusabscess, mandibular abscess and submandibular abscess.

A total of 6 patients who were hospitalized in East Indonesia various diagnoses, such as facialabscesses, mandibular abscesses, cheek abscesses, and maxillary abscesses.

Total 21 patients treated at Dr. Wahidin Sudirohusodo Hospital with various diagnoses such as mouth abscess and periapical abscess.

From the results of statistical tests $p$ value 0.05 , which means that there is no significant difference between cases of maxillofacial abscess in the rainy and dry seasons. Figure 1.

This diagram shows the overall data of patients with abscesses maxillofacial and rainfall data in South Sulawesi from 2011 - 2018, indicating that of abscess maxillofacial there were 48 casesin the rainy season and in the dry season there were 44 cases.

\section{Discussion}

Odontogenic infection is one of the most common infections in humans. In most patients this infection is minor or underestimated and is often 
Table 2 Patient data on region abscess maxillofacial at Unhas Teaching Hospital

\begin{tabular}{lcl}
\hline Time & Total & Diagnosis \\
\hline March 2013 & 1 & Zygomaticus Abscess \\
January 2015 & 1 & Mandibular Abscess \\
August 2015 & 1 & Mandibular Abscess \\
November 2015 & 2 & Mandibular Abscess \& Submandibules \\
March 2016 & 1 & Mandibular Abscess \\
May 2016 & 1 & Submandibular Abscess \\
September 2016 & 1 & Mandibular Abscess \\
January 2017 & 1 & Submandibular Abscess \\
February2017 & 1 & Submandibular Abscess \\
May 2017 & 1 & Submandibular abscess
\end{tabular}

Table 3 Patient Data on Region Abscess Maxillofacial The University Hospital of Eastern Indonesia

\begin{tabular}{lcl}
\hline Time & Total & Diagnosis \\
\hline January 2016 & 1 & Abscess facial \\
April 2016 & 2 & Abscess Mandible \\
June 2016 & 1 & Abscess Buccal \\
September 2016 & 1 & Abscess maxilla \\
October 2016 & 1 & Abscess Mandible \\
\hline
\end{tabular}

\begin{tabular}{lcl} 
Table 4 & Patient data on region abscess maxillofacial at Dr. Hospital Wahidin Sudirohusodo \\
\hline Time & Total & Diagnosis \\
\hline February 2016 & 2 & Oral Abscess \\
March 2016 & 1 & Mouth Abscess \\
April 2016 & 1 & Mouth Abscess \\
May 2016 & 1 & Mouth Abscess \\
September 2016 & 1 & Mouth Abscess \\
November 2016 & 1 & Mouth Abscess \\
December 2016 & 1 & Mouth Abscess \\
April 2017 & 2 & Mouth Abscess \\
November 2017 & 1 & Mouth Abscess \\
December2017 & 1 & Mouth Abscess \\
January 2018 & 1 & Mouth Abscess \\
February 2018 & 1 & Mouth \& Periapical Abscess \\
March 2018 & 1 & Mouth Abscess \\
May 2018 & 2 & Mouth \& Periapical Abscess \\
August 2018 & 2 & Mouth \& Periapical Abscess \\
September 2018 & 1 & Mouth \& Periapical Abscess \\
October 2018 & 1 & Mouth Abscess \\
\hline
\end{tabular}

characterized by spontaneous drainage along the gingival tissue in the affected tooth. ${ }^{4}$ Odontogenic infections are the most common oral cavity infections. Odontogenic infections can be the beginning or continuation of periodontal, pericoronal, trauma, or post-surgical infections. ${ }^{2}$ Odontogenic infections are also more often caused by several types of bacteria such as streptococcus. The infection can be localized or can spread quickly to the other side of the face. ${ }^{3}$ 
Table 5 The incidence in rainy and drought season throught the year

\begin{tabular}{|c|c|c|c|c|c|c|}
\hline & \multicolumn{5}{|c|}{ Abscess } \\
\hline & & Mean & Minimum & Maximum & Total & Value \\
\hline \multirow{2}{*}{2011} & Rainy & 0.00 & 0 & 0 & 0 & \multirow{2}{*}{0.138} \\
\hline & Dry Season & 0.33 & 0 & 1 & 2 & \\
\hline \multirow{2}{*}{2012} & Rainy Season & 0.67 & 0 & 2 & 4 & \multirow{2}{*}{0.465} \\
\hline & Dry Season & 0.33 & 0 & 1 & 2 & \\
\hline \multirow{2}{*}{2013} & Rainy & 1.11 & 0 & 3 & 10 & \multirow{2}{*}{1.000} \\
\hline & Dry Season & 1.00 & 0 & 2 & 3 & \\
\hline \multirow{2}{*}{2014} & Rainy Season & 0.57 & 0 & 1 & 4 & \multirow{2}{*}{0.157} \\
\hline & Dry Season & 1.80 & 0 & 4 & 9 & \\
\hline \multirow{2}{*}{2015} & Rainy Season & 1.38 & 0 & 4 & 11 & \multirow{2}{*}{0.654} \\
\hline & Dry Season & 0.75 & 0 & 1 & 3 & \\
\hline \multirow[b]{2}{*}{2016} & Rainy Season & 2.17 & 0 & 5 & 13 & \multirow[b]{2}{*}{0.667} \\
\hline & Dry Season & 2.67 & 1 & 6 & 16 & \\
\hline \multirow{2}{*}{2017} & Rainy Season & 0.33 & 0 & 1 & 2 & \multirow{2}{*}{0.075} \\
\hline & Dry Season & 1.00 & 0 & 2 & 6 & \\
\hline \multirow{2}{*}{2018} & Rainy Season & 0.67 & 0 & 2 & 4 & \multirow{2}{*}{1.000} \\
\hline & Dry Season & 0.50 & 0 & 1 & 3 & \\
\hline
\end{tabular}

\section{${ }^{*}$ Independent $t$ \\ test ${ }^{* *}$ Mann Whitney Tes}

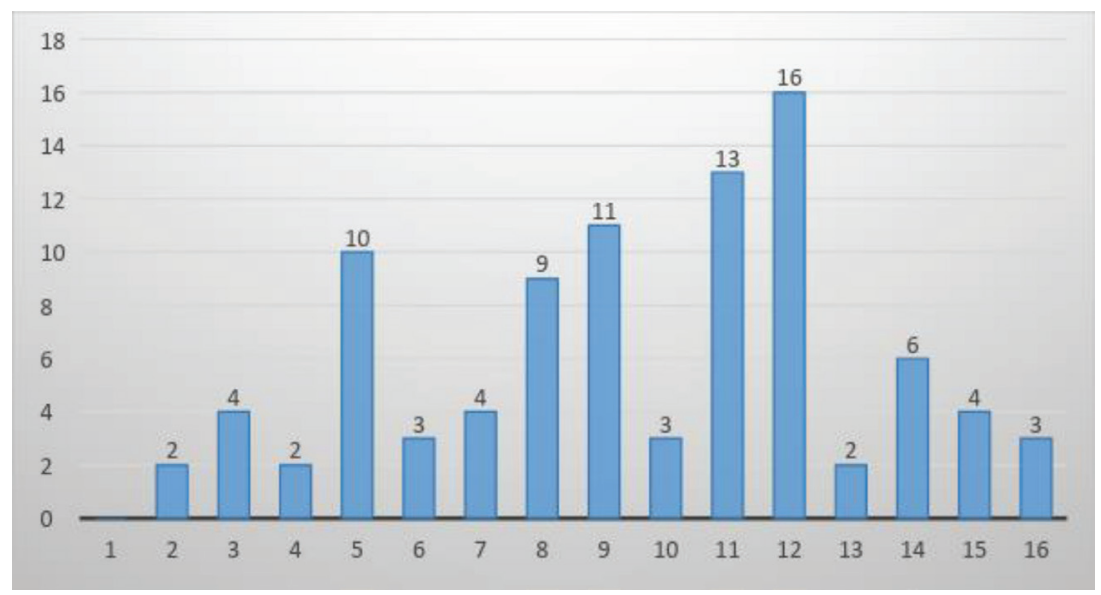

Figure 1 Diagram of the amount of abscesses in the dry and rainy season

The bacteriological agents involved in causing dental abscesses consist of a mixture of anaerobic and facultative anaerobic bacteria. Data collection from culture and molecular studies shows that more than 460 unique taxa bacteria belonging to 100 genera and 9 phyla have been identified in various types of endodontic infections. Anaerobic bacteria are more abundant than facultative with a ratio that varies between 1.5 and 3: 1 in mixed infections. ${ }^{5}$ The majority of oral abscesses are caused by oral cavity bacteria, such as species streptococcus, species staphylococcus, species prevotella, eikenella corrodens and others that migrate through decaying root canals or periodontal pockets into the bones. ${ }^{4}$ In a study conducted by Aschoff and Wever stating that oral bacteria including abscess-causing germs showed the highest growth rate at $37^{\circ} \mathrm{C}$. In humans, thermoregulation is very effective in keeping the body's core temperature constant while air temperature can significantly change the temperature of the body area outside of Depending on the air temperature from $5 \mathrm{C}$ to $50 \mathrm{C}$, the temperature of the hand or foot ranges from 16 to $40 \mathrm{C}$, and the forehead is 27-39 C, while the core temperature remains stable between 36.5 and $38 \mathrm{C}$, so the human temperature remains optimal for bacterial growth. ${ }^{6}$

The majority of previous studies focused on air temperature and experienced several limitations, namely only involving small numbers of patients and only involving one institution. Research that only includes one institution has the possibility of causing selection bias depending on the hours of practice, and a short study period can overlook high variations in weather parameters. When these and other relevant confounding factors have been considered, the question of whether the occurrence of oral abscesses is affected by outside temperature or other environmental factors remains unanswered. Therefore, the aim of the current retrospective and multicenter study is to investigate the effect of meteorological parameters, including daily average barometric temperature and pressure, on the frequency of oral abscesses in a large number of patients. To validate each observed relationship, the effects of confounding variables and parameters reflecting the work habits of a local dental facility (such as working days, working days and months) are also considered. ${ }^{4}$

The results of this study were not significant in the designation of the relationship between region abscess maxillofacial and climate in South Sulawesi, because it was caused by several factors including the number of samples and the interval of data used, as well as environmental factors such as temperature and air pressure.

The number of samples has an important influence on the results of this study. In this study, researchers used a sample of 92 samples and obtained insignificant results on the relationship of region abscess maxillofacial to climate in South Sulawesi, whereas in a study conducted by Seemann $\mathrm{R}$ et al in 2015 using a sample of 19,225 significant results were obtained for abscess regional relationships. maxillofacial with climate. ${ }^{4}$ Therefore, the above shows that the number of samples used has an important influence on the relationship ofregion abscess maxillofacial to climate.

In addition, the interval of data used is also one of the factors that can influence the results of the 
study. In this study, researchers used data at intervals of 8 years, whereas in studies that obtained significant results, the research conducted by Seemann et al. ${ }^{4}$ used data with a time interval of 14 years. ${ }^{4}$

The third factor that can influence the results of the study is temperature. Temperatures in South Sulawesi tend to be higher, the difference between the temperature during the rainy season and the temperature during the dry season in South Sulawesi is also not large or below 10C, whereas according to the conduction method, high temperatures will move to areas that have lower temperatures, so that the heat in the room will move and affect the body temperature of the subject. In contrast to research conducted in areas that have cooler temperatures. When the body is in a cooler room and the body temperature is hotter, of course the body will emit heat and the body temperature will drop. ${ }^{7}$ This increase in dental abscess can be caused because in low temperature conditions, the oxygen level will be a little too vice versa. If the oxygen level is small, this can benefit facultative anaerobic and anaerobic bacteria which are the dominant bacteria from abscesses. So that in areas that have low temperatures, the incidence of abscesses will increase. ${ }^{8}$

Other factors that can cause the results of this study are not significant, namely air pressure. There is a relationship between barometric pressure and the occurrence of abscesses. In accordance with previous research that if barometric pressure eats the number of occurrences of abscesses will increase, and vice versa. This finding confirms the assumptions of the number of abscesses is significantly higher during cyclone weather conditions, especially during low barometric pressures. ${ }^{4}$

\section{Conclusion}

Research on the relationship between region abscess maxillofacial and climatein South Sulawesi shows that as many as 31 abscess cases in Ibnu Sina Hospital, 9 abscess cases in Unhas Hospital, 3 cases of abscess in UIT Hospital occurred when rainfall was high, while 27 cases of RS abscesses Ibnu Sina, 2 RSP Unhas abscess cases, 3 cases of UIT Hospital abscess occurred when rainfall was low. This indicates that there is a relationship between the development of abscesses when high rainfall or when barometric pressure is low.

\section{Acknowledgment}

Further research with a greater number of cases and a wider range of regions can be done to be able to prove with certainty that there is a relationship between the growth of abscesses in the region maxillofacial and the climate in an area.

\section{Conflict of Interest}

The authors report no conflict of interest.

\section{References}

1. Sousa JC, et al. Apical periodontitis and related risk factors: Cross sectional study. J of Cranio Maxillofac Surg 2015;56: 226-232.

2. Kojima Y, Kojima M, Sakaguchi K, et al. Case report: a case of buccal abscess from an impacted wisdom tooth in an elderly. Case Report Dent 2016

3. Chatterji P, Goyal I. Temporoparietal and infratemporal fossa abscess as a complication of dental extraction. Asian J Med Sci 2018;9: 57-60.

4. Seemann R. The frequency of dental abscesses increases in periods of low barometric pressure. J Cranio Maxillofac Surg 2015;43: 1843-1848.

5. Matthews DC, Sutherland S, Basrani B. Emergency management of acute apical abscesses in the permanent dentition: a systematic review of the literature. J Can Dent Assoc 2003;69: 660 .

6. Prakash SK, Shweta. Dental abscess: a microbiological review. Dent Rest J 2013;10.

7. Aschoff J, Wever R. Anisotropy of the skin for heat transfer. Pflugers Arch Gesamte Physiol Menschen Tiere 1959;269: 130-134.

8. Chanda MH. Canina fossa abscess and treatment. J Dentomaxillofac Sci 2018;3: 54-57.

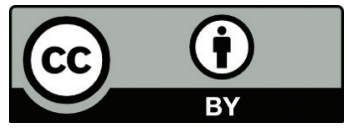

This work is licensed under a Creative Commons Attribution 